\title{
Verzeichnis der R-Grafiken
}

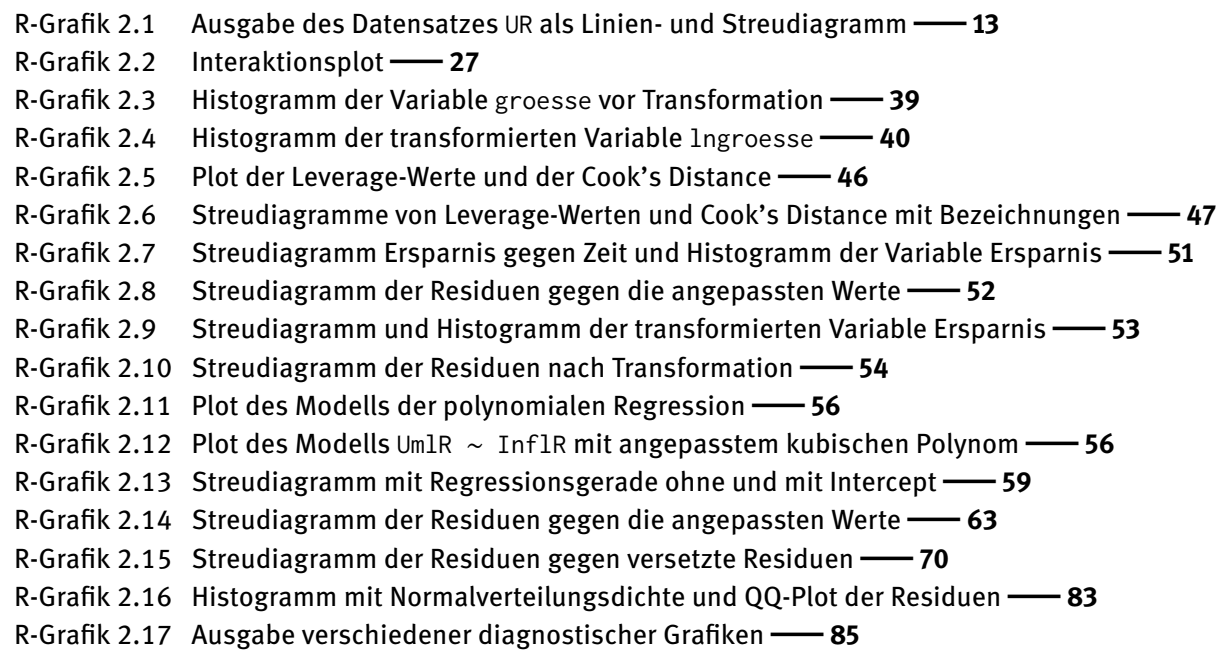

R-Grafik 3.1 Vergleichende Liniendiagramme - 97

R-Grafik 3.2 Streudiagramm Zinsspread gegen Nominalzins - 101

R-Grafik 4.1 Plot der mittleren marginalen Effekte (ohne Interaktion) - 133

R-Grafik 4.2 Plot des mittleren marginalen Effekts bei Interaktion - 144

R-Grafik 4.3 Plot der modellierten Wahrscheinlichkeiten - 145

R-Grafik 4.4 Plot von Leverage-Werten, Delta- $\chi^{2}$ und Delta- $\beta-149$

R-Grafik 4.5 Streudiagramm einkommen gegen Logit $\eta-152$

R-Grafik 4.6 Ausgabe der ROC-Kurve - 161

R-Grafik 4.7 Plot der Liftkurve mit Durchschnittslinie - 165

R-Grafik 5.1 Plot des Klassifikationsbaums - 172

R-Grafik 5.2 Plot der Komplexitätsparameter eines Baums - $\mathbf{1 8 0}$

R-Grafik 5.3 Plot des Regressionsbaums - 183

R-Grafik 5.4 Random Forest: Grafische Ausgabe der Wichtigkeit der Variablen —199

R-Grafik 6.1 Plot der Korrelationsmatrix - 210

R-Grafik 6.2 Biplot der ersten beiden rotierten Hauptkomponenten $-\mathbf{2 1 6}$

R-Grafik 7.1 Liniendiagramm des Kursverlaufs des DAX30 - 221

R-Grafik 7.2 Korrelogramme der quadrierten DAX-Renditen - 225

R-Grafik 7.3 Liniendiagramm der Zeitreihe ADI - 242

R-Grafik 7.4 Plot der ersten Differenz der Zeitreihe ADI - 244

R-Grafik 7.5 ACF und PACF der ersten Differenz - 244

R-Grafik 7.6 QQ-Plot der Residuen des ARIMA(4,1,0)-Modells - 246

R-Grafik 7.7 Verschiedene diagnostische Plots $-\mathbf{2 4 7}$

R-Grafik 7.8 Liniendiagramm der Zeitreihe mit Forecast aus einem ARIMA-Modell - 249

R-Grafik 7.9 Liniendiagramme der SAP-Kurse und der stetigen Renditen - 259 
R-Grafik 7.10 ACF und PACF der Renditen (oben) und der quadrierten Renditen (unten) von SAP -260

R-Grafik 7.11 McLeod-Li-Test auf Heteroskedastizität - 261

R-Grafik 7.12 Liniendiagramm der Residuen des GARCH(1,1)-Modells - 264

R-Grafik 7.13 Liniendiagramme der Renditen und der modellierten Varianz -265

R-Grafik 8.1 Liniendiagramme der Mittelwerte der abnormalen Renditen - $\mathbf{2 8 4}$ 